\title{
TABlaturas PARA PERCUSSÃO POPUlAR: NOTAÇÃO MUSICAL ALTERNATIVA PARA ATABAQUES DA UMBANDA E DO CANDOMBLÉ KETU
}

\author{
Tablatures for Popular Percussion: \\ alternative musical notation for Umbanda \\ and Candomblé Ketu drums
}

\author{
Tablaturas para Percusión Popular: notación \\ musical alternativa para los tambores de \\ umbanda y candomblé ketu
}

LuCiano da SiLva CANDEMiL
Universidade Federal do Paraná
lucianocandemil@hotmail.com

Resumo: Este trabalho apresenta a elaboração da Tablatura para Percussão, uma notação musical alternativa para os atabaques da umbanda e candomblé ketu. O objetivo foi desenvolver uma escrita para facilitar a aprendizagem dos ritmos tocados nos terreiros no Vale do Itajaí, em Santa Catarina. Surge da interface entre pesquisas sistemáticas, explorações informais, atividades de ensino/aprendizagem e da experiência do campo. Conta com revisão bibliográfica da área da educação musical, etnomusicologia e de estudos sobre música afrorreligiosa. O modelo foi inspirado no sistema TUBS, de Koeetting, jogo da amarelinha, analogia da fita métrica; e em parâmetros musicais aplicados às músicas de matriz africana, como linha-guia. A Tablatura para Percussão tem uma grafia simples e sintética, com o mínimo de informações necessárias à execução musical.

Palavras-chave: Percussão popular. Notação musical alternativa. Religiões afro-brasileiras.

Abstract: This work presents the elaboration of the Tablature for Percussion, an alternative musical notation for the drums of Umbanda and Candomble Ketu religions. The objective was to develop writing to facilitate the learning of the rhythms played at the temples in the Itajai Valley, Santa Catarina State. It emerges from the interface between systematic research, informal explorations, teaching/ learning activities and field experience. It was carried out with bibliographic review in the area of Music Education, Ethnomusicology, and studies on Afro-religious music. The model was inspired by the TUBS System, by Koeetting, the Hopscotch game, a tape measure analogy; and in musical parameters applied to songs of African origin, as a timeline. Percussion Tablature has a simple and synthetic writing, with the minimum of information necessary for musical performance, which has helped people with rhythmic difficulties.

Keywords: Popular percussion. Alternative musical notation. Afro-Brazilian religions.

Resumen: Este trabajo presenta la elaboración de la Tablatura para Percusión, una notación musical alternativa para los tambores de umbanda y candomblé ketu. El objetivo fue desarrollar la escritura para facilitar el aprendizaje de los ritmos tocados en los terreiros del Valle de Itajaí, en Santa Catarina. Surge de la interfaz entre la investigación sistemática, las exploraciones informales, las actividades de enseñanza/aprendizaje y la experiencia de campo. Tiene una revisión bibliográfica en el área de educación musical, etnomusicología y estudios sobre música afro-religiosa. El modelo se inspiró en el sistema TUBS, en Koeetting, juego de amarelinha, analogía de la cinta métrica; y en parámetros musicales aplicados a canciones de origen africano, como pauta. La Tablatura para Percusión tiene una ortografia simple y sintética, con el mínimo de información necesaria para la interpretación musical.

Palabras clave: Percusión popular. Notación musical alternativa. Religiones afrobrasileñas. 


\section{INTRODUÇÃO}

Quando se faz uma pesquisa sobre a música de uma determinada cultura, poderemos ter como desdobramento um novo olhar para as nossas práticas. ${ }^{1}$ Nesse sentido, a experiência da "bimusicalidade"2 (Hood, 1960) adquirida no últimos anos como pesquisador de músicas de matriz africana e percussionista convidado de casas religiosas de umbanda e candomblé ketu na região do Vale do Itajaí, em Santa Catarina, foi suficiente para buscar uma notação musical alternativa para os ritmos dos atabaques e tambores similares.

Surge então a Tablatura ${ }^{3}$ para Percussão Popular, uma proposta de escrita musical não convencional, feita de percussionista para percussionista, com o objetivo de facilitar a aprendizagem dos ritmos tocados nos terreiros, principalmente para aquelas pessoas que apresentam dificuldades ritmicas. ${ }^{4}$ Observei que certos tipos de pessoas, em especial aquelas que têm mais facilidade de aprender pelo modo visual, tiveram melhores resultados com o uso da tablatura do que por meio de onomatopeias. Além disso, constatei a falta de interesse pela leitura convencional de música.

A Tablatura para Percussão nasce da interface entre a educação musical e a etnomusicologia, como resultado de explorações musicais informais, de pesquisas sistemáticas e de experiências diversas de ensino/aprendizagem de ritmos, individual e coletivo. Por meio de uma escrita simplificada, pretende ser também uma forma de registro para auxiliar a memória, transcrições e análises musicais. Cabe ressaltar que o diálogo entre as áreas supracitadas já havia sido sugerido por Queiroz (2010).

Em paralelo à experiência prática e teórica, foi realizada uma revisão bibliográfica multidisciplinar, que contou com autores da educação musical (Almeida; Pucci, 2011; Arroyo, 2000; Kleber, 2006), da etnomusicologia (Blacking, 2007; Cardoso, 2006; Fonseca, 2003); bem como de estudos sobre música afrorreligiosa (Braga, 2005; Prandi, 2005) e cultura (Santos, J., 2006; Tylor, 1871).

Sabe-se que as culturas são dinâmicas, o que pressupõe mudanças nas relações humanas, no uso do tempo e do espaço, nos materiais e tecnologias disponiveis, bem como nas maneiras como o "conhecimento é expresso" (Santos, J., 2006, p. 50). Se a cultura também é marcada pela "capacidade de trocar simbolicamente" (Kleber, 2012, p. 27) todo um conjunto de saberes, "habilidades e hábitos de uma sociedade" (Tylor, 1871, p. 1), nos quais se incluem as músicas, torna-se importante conhecer os instrumentos musicais

\footnotetext{
1 Projeto de pesquisa de doutorado em Música/Etnomusicologia.

2 Para estudar a música do outro é necessário adquirir uma segunda musicalidade, a musicalidade do outro, incluindo o modo de aprendizagem (Hood, 1960).

3 A tablatura é um tipo de notação não convencional. No caso do violão e guitarra, a tablatura indica onde os dedos devem ser posicionados. A Tablatura para Percussão faz uma relação temporal entre manulação e timbres. 4 Dificuldade de manter um andamento constante, de executar subdivisões rítmicas, de relacionar timbre e técnica, de ordenar a manulação, bem como de tocar simultaneamente com outras pessoas.
} 
(Almeida; Pucci, 2011, p. 19), perceber como são tocados e como as pessoas interagem em torno deles (Blacking, 2007, p. 204).

Aprender música não é uma exclusividade das salas de aula (Wille, 2005, p. 39), mas uma atividade que pode acontecer em qualquer ambiente formal ${ }^{5}$ ou informal. Por exemplo, as casas religiosas afro-brasileiras, os grupos de capoeira e as escolas de samba são espaços de tradição oral que possuem suas próprias formalidades e sistemáticas. Então a oralidade e novas práticas de ensino podem ser estratégias para atender a diversidade musical brasileira (Arroyo, 2000, p. 89; Kleber, 2006, p. 257). No entanto, apesar do sucesso midiático de alguns grupos ${ }^{6}$ afromusicais, ainda prevalece a "grande dificuldade de aceitação do saber empírico e uma supervalorização da cultura letrada" (Farias, 2011, p. 85).

\section{DA ORALIDADE À ESCRITA}

O candomblé ketu e a umbanda são considerados religiões afro-brasileiras iniciáticas, que estão alicerçadas na tradição oral. Enquanto o candomblé ketu cultua os orixás, as divindades de origem africana que simbolizam as energias da natureza, na umbanda são cultuados os orixás e diversos tipos de espíritos reencarnados, como os de antepassados indigenas, antigos escravos e crianças. Do ponto de vista doutrinal, o candomblé ketu está mais voltado para os cultos africanos, enquanto a umbanda é uma mistura das raízes africanas, do catolicismo, kardecismo e de práticas espirituais indigenas.

Independentemente dos "usos e funções da música" (Merriam, 1964), tanto nos terreiros de candomblé ketu quanto em grande parte das casas de umbanda a música é de extrema importância para a realização dos rituais. Nesse contexto, a música tem caráter funcional, com destaque para a função comunicativa e de sustentação do culto (Cardoso, 2006, p. 185; Lody; Sá, 1989 , p. 61) e para os atabaques que estão presentes em quase todos os eventos religiosos e sociais (Brandão, 2015, p. 115).

A transmissão dos conhecimentos musicais no universo das religiões afro-brasileiras já foi objeto de estudo de algumas pesquisas. De maneira geral, vários autores verificaram que prevalece a oralidade, que se dá pela observação, pela escuta, por processos de “imitação" (Braga, 2005, p. 101. Prass, 2004, p. 151), pela participação familiar e inserção da criança nos rituais (Lunelli, 2015, p. 8-9), pela "integração comportamental" (Cardoso, 2006, p. 207), bem como um olhar atento para a dança que os aprendizes devem ter, em especial no caso do candomblé ketu.

No entanto, diferentemente de tempos antigos, atualmente muitas pessoas que praticam a oralidade têm o dominio da escrita. Essa "oralidade não pura" tem sido facilitada pelo acesso à informação fora do espaço dos terrei-

\footnotetext{
5 Sobre educação formal, informal e não formal, ver Gohn (2006, p. 30);

6 Grupos baianos como o Olodum, Ilê Ayê, Timbalada e Filhos de Gandhy resgataram suas tradições ao formatar a base da sua musicalidade com os ritmos dos terreiros de candomblé (Guerreiro, 2000, p. 51).
} 
ros. Muitos adeptos procuram outras fontes para ampliar seu conhecimento. Inclusive, são os próprios iniciados nas religiões que produzem e compartilham os materiais que ficam acessiveis para todos, insiders e outsiders.

Por exemplo, é possivel encontrar uma vasta diversidade e quantidade de conteúdo em canais no YouTube, sites, blogs, perfis nas redes sociais, etc. Algumas dessas plataformas digitais são utilizadas como meio de comunicação, servindo para trocar informações cotidianas dos terreiros, agendar consultas, repassar recados e divulgar as festas e rituais públicos. Em algumas regiões do país, é notável a presença dos aparelhos de celular no meio das cerimônias religiosas. Ou seja, de alguma forma a escrita e a tecnologia estão presentes.

Mas se por um lado "as formas de aprendizagem no candomblé [e na umbanda] são múltiplas e complementares" (Cardoso, 2006, p. 213), no que se refere às músicas e aos ritmos tocados nos atabaques, normalmente eles acontecem sem o uso de algum tipo de notação musical (Silva; Vicente, 2008, p. 19). Então, talvez seja possivel dizer que se trata de uma "oralidade tecnológica", "oralidade mediada", "oralidade tecnologicamente mediada", "oralidade não presencial", ou ainda "oralidade virtual".

Sobre o compartilhamento de conteúdo musical na internet, como qualquer outro tipo de conhecimento, cabe ressaltar que muitas casas afrorreligiosas constituíram ao longo do tempo uma vasta comunidade, chamada de família de santo, que se encontra espalhada por todo o território brasileiro e até nos países vizinhos (Braga, 2013). Consequentemente, naquelas cidades mais distantes e onde haja a carência de músicos e percussionistas, as informações compartilhadas podem ajudar o aprendizado das cantigas e dos ritmos.

Sobre essa questão, durante a pesquisa de campo realizada na região do Vale do Itajaí, em Santa Catarina, foi constatado que muitos terreiros de candomblé ketu e umbanda, principalmente do primeiro, precisam contratar percussionistas de outra casa, até de outras cidades, para poderem realizar os seus rituais. No caso da umbanda, em algumas casas apenas um ou dois ritmos diferentes são tocados numa mesma noite. Por outro lado, é notável o interesse de muitos adeptos pela formação de grupos de estudos, oficinas de percussão e pela compra de apostilas (Monteiro, 1995) e livros de cantigas (Oliveira, 2012).

No entanto, esses materiais apenas indicam o nome do ritmo e não apresentam alguma forma de notação, com raras exceções (Sena, 2014, 2015, 2017). Dos materiais voltados para a percussão afrorreligiosa que utilizam a notação convencional, podemos acrescentar os livros de Calabrich e Silva (2017), Silva e Vicente (2008) e Brundage (2010) e as pesquisas de Braga (1997) e Cardoso (2006). Em relação às cantigas, temos os trabalhos de Alvarenga (1946), Lühning (1990) e Garcia (2001) e os livros de Barros (2009a, 2009b). Cabe ressaltar que, normalmente, as teses e dissertações não são procuradas pelos membros das religiões. 
Portanto, apesar de o candomblé ketu e a umbanda estarem apoiados na tradição oral, a escrita tem sido cada vez mais usada como uma estratégia para a manutenção da própria religião. Inclusive a escrita tem sido usada por muitos regentes espirituais para ajudar a memória (Bastide, 2001, p. 122). Uma das incentivadoras da escrita foi a Mãe Stella de Oxóssi, uma das ialorixás mais conhecidas e respeitadas do Brasil. Mesmo ciente da importância da oralidade, ela acreditava que registrar a religião era uma maneira de preservar a tradição (Santos, M., 2010, p. 31). "Religião é cultura. A religião estática perecerá [...] a tradição somente oral é dificil” (Santos, M., 2010, p. 35). Diante disso e atenta às novas tecnologias, publicou alguns livros ${ }^{7}$ e compartilhou seu conhecimento em entrevistas, impressos variados, em canal no YouTube e criou um aplicativo para celular. ${ }^{8}$

Entretanto, se olharmos as produções disponiveis nas "prateleiras" sobre a umbanda e o candomblé ketu, encontraremos diversas abordagens de caráter histórico, sociológico, antropológico e filosófico. Dessas, teremos trabalhos de cunho êmico, ${ }^{9}$ escritos pelos babalorixás ${ }^{10}$ e membros seniores ${ }^{11}$ das comunidades. Mas as opções focalizadas na música serão poucas, sendo ainda mais raras aquelas sobre os ritmos tocados nos atabaques. Por conta de tudo isso, considerei oportuno pensar na Tablatura para Percussão como uma notação musical alternativa, que fosse simples e sintética, para auxiliar a transmissão dos ritmos tocados nos atabaques do candomblé ketu e da umbanda.

\section{APRENDIZAGEM MUSICAL E PARÂMETROS RÍTMICOS}

Para facilitar a compreensão do desenvolvimento da Tablatura para Percussão, primeiro é apresentado o processo tradicional de aprendizagem dos atabaques que acontece no candomblé ketu e alguns parâmetros rítmicos pertinentes. Essa escolha está pautada na complexidade rítmica, na quantidade de ritmos diferentes, por motivações históricas, pela existência de pesquisas específicas e pelo fato de a formação instrumental ser mais padronizada do que na umbanda.

Conforme a Figura 1, o conjunto dos instrumentos do candomblé ketu é formado pelos três atabaques, lé (agudo), rumpi (médio) e rum (grave); e pelo gã $\tilde{a}^{12}$ (ou agogô) (Cardoso, 2006, p. 46). Nessa formação, haverá funções musicais distintas. Enquanto o atabaque rum é o solista, o que executa variações para marcar os passos da dança, os demais instrumentos formam uma base musical.

\footnotetext{
7 Mãe Stella de Òșósi (2006), Santos, M. (2010), Santos e Peixoto (2014).

8 Santos, M. (2017).

9 "Êmico faz parte da dicotomia êmico/étnico criada por Kenneth Pike. Sucintamente, êmico se refere à visão autóctone, enquanto ético diz respeito à ótica de alguém fora da cultura" (Cardoso, 2006, p. 65).

${ }_{10}$ Reis (2000), Ogbebara (1998), Beniste (2001), Vallado (2008).

${ }^{11}$ Brandão (2015), Maurício (2009).

${ }^{12}$ A diferença entre o agogô e o gã é que o primeiro tem duas campânulas e o segundo, apenas uma (Cacciatore, 1977, p. 41, 130).
} 


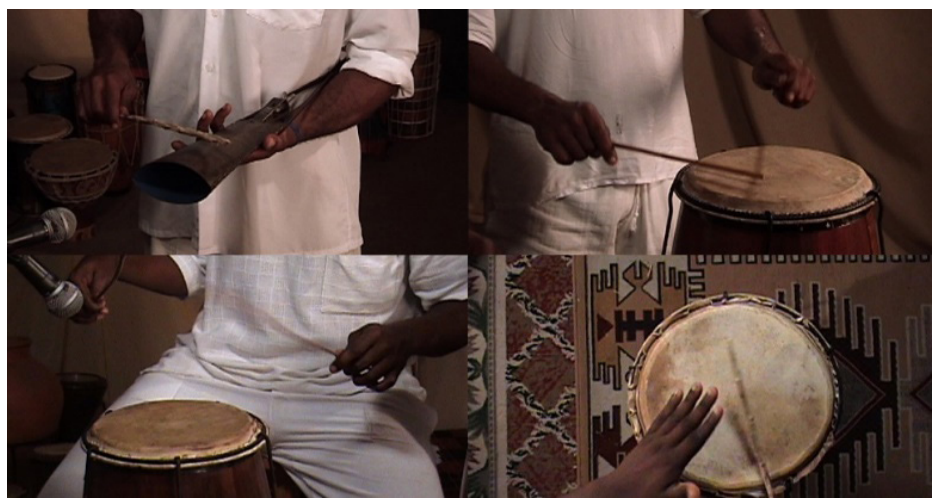

Figura 1: O gã e o trio de atabaques.

Fonte: A Orquestra... (2011).

Essa base musical tem como referência um padrão sonoro, um tipo de ostinato, que é tocado pelo gã e reforçado pela mão direita ${ }^{13}$ nos atabaques lé e rumpi, enquanto a mão esquerda executa notas complementares nesses tambores. Esse padrão rítmico é conhecido no meio acadêmico por timeline (Arom, 2001; Nketia, 1974), claves (Peñalosa, 2009) ou linha-guia (Fonseca, 2003). Adotarei este último.

Essas linhas-guia, normalmente encontradas nas músicas de matriz africana, são frases musicais curtas e circulares ${ }^{14}$ que ordenam a execução do conjunto instrumental e auxiliam a entonação das cantigas (Cardoso, 2006, p. 148; Kubik, 1979, p. 109), bem como servem como identificadores dos orixás. Outra peculiaridade está relacionada com a forma de tocar os instrumentos. Na grande maioria dos ritmos, o gã é tocado com uma aguidavi, ${ }^{15}$ o lé e o rumpi são tocados com duas, enquanto o atabaque rum é articulado com uma aguidavi em uma das mãos e com a outra mão diretamente na pele, o que permite tirar vários timbres nesse tambor.

Toda essa organização vai interferir na sequência de aprendizagem dos toques. Primeiro o iniciante aprende a tocar a linha-guia no gã depois passa para os atabaques lé e rumpi, nessa ordem, e finalmente, depois de muito tempo de experiência, são ensinadas as instruções para tocar o rum (Barros, 2009a, 2009; Cardoso, 2006; Fonseca, 2003).

Por sua vez, as linhas-guia possuem uma estrutura interna que é formada por "unidades mínimas de tempo" chamadas de pulsações elementares (Lacerda, 2014, p. 210). Ressalta-se que, por conta do caráter circular das músicas de matriz africana, a aprendizagem nos terreiros é mediada pela linha-guia e não pela contagem de tempos ou pulsos equidistantes, como se faz no âmbito da música popular brasileira. Na Figura 2, temos a linha-guia do vassi, o ritmo mais tocado no candomblé ketu, (Lühning, 1990, p. 120), formada num ciclo com 12 pulsações elementares.

\footnotetext{
13 Esse exemplo é para os destros.

${ }^{14}$ Frases circulares são frases que se repetem constantemente.

${ }^{15}$ Aguidavi: vareta artesanal feita com galhos de árvore.
} 


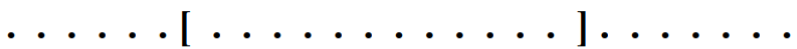 \\ $[\mathbf{X} \cdot \mathbf{X} \cdot \mathbf{X} \mathbf{X} \cdot \mathbf{X} \cdot \mathbf{X} \cdot \mathbf{X}]$ \\ Ciclo de 12 pulsações elementares}

Figura 2: Linha-guia do vassi. Fonte: elaboração própria.

A representação gráfica é uma proposta de Kubik (1979), na qual o "ponto" equivale a uma pulsação elementar, enquanto a letra "X" marca a localização do ataque sonoro. Recebendo outros nomes, essa mesma linha-guia do vassi é muito encontrada na África Ocidental (Lacerda, 2014, p. 239). Como veremos adiante, essas pulsações elementares podem ser relacionadas às caixas do sistema TUBS e constituem a base para a elaboração da Tablatura para Percussão.

\section{A ElABORAÇÃo DA TABlatURA PARA PERCUSSÃo}

No universo da música popular brasileira, diversas práticas adotam soluções que suprem o uso da notação musical convencional. Esse é o caso da cifra, um tipo de representação gráfica que por meio de letras do alfabeto indica o acorde que deve ser tocado, porém não aponta como deve ser feito, nem em que parte do instrumento deve ser realizado, assim como não fornece informações rítmicas. Ademais, a mesma cifra pode ser empregada para vários instrumentos. Portanto, a cifra é um tipo de notação musical que auxilia a memória de músicos que possuam certo conhecimento idiomático do instrumento e do repertório. Foi com esse propósito que surgiu o primeiro esboço da Tablatura para Percussão.

No periodo entre 2000 e 2004, eu não tinha formação acadêmica em música, não dominava a escrita convencional, não conhecia a educação musical e a etnomusicologia, muito menos o universo das pesquisas. Porém, como fazia muitas explorações musicais percussivas, foi preciso criar um tipo de registro para dar conta de observações espontâneas e para transcrever as gravações de aulas ${ }^{16}$ particulares, feitas em fitas cassete. Diante disso, tinha que ser uma escrita simples e rápida, mais preocupada com os timbres, manulação ${ }^{17}$ e com a divisão rítmica.

Posteriormente, em meados de 2018, como parte de um projeto de doutorado em música, tive a ideia de aproveitar essa solução de notação alternativa para ajudar as pessoas com dificuldade na aprendizagem ${ }^{18}$ dos ritmos da umbanda e do candomblé ketu. Então, partindo do princípio que a mesma

\footnotetext{
${ }^{16}$ Aulas de ritmos do candomblé ketu com Bira Reis (in memoriam), Salvador, 2000. Aulas de ritmos da África Ocidental com Nicolas Malhomme (in memoriam), Florianópolis, 2001-2004.

17 Divisão de mãos.

${ }^{18}$ Constatação feita durante aulas particulares, grupos de estudos e oficinas.
} 
lógica seria de fácil aceitação, a Tablatura para Percussão foi revisada e reformulada, tendo como suporte a experiência do campo, a prática e a teoria.

Assim, o novo modelo da Tablatura para Percussão foi elaborado a partir de alguns parâmetros rítmicos estabelecidos pela etnomusicologia para as músicas de matriz africana, como: circularidade (Agawu, 2006; Oliveira Pinto, 2001), linha-guia ou timeline (Nketia, 1974; Sandroni, 2001), e pulsação elementar (Kubik, 1979), todos já mencionados aqui. Para o design visual, utilizei como inspiração o TUBS, ${ }^{19}$ uma escrita musical criada em 1962 por Philip Harland para ritmos populares (Koetting, 1970), o jogo da amarelinha e a analogia da fita métrica. A Figura 3 mostra quatro exemplos de linhas-guia que são tocadas em idiofones.

The time-unit box system

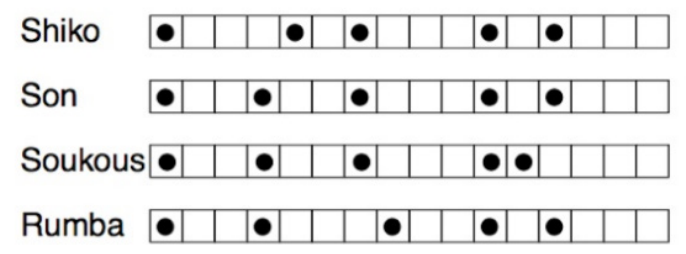

Figura 3: TUBS. Fonte: Hein (2015, p. 3).

Conforme a Figura 3, o TUBS é um conjunto de caixas vazias que correspondem às pulsações elementares de um ciclo rítmico ou à divisão rítmica de uma fórmula de compasso. Nesse exemplo temos 16 pulsações elementares que equivalem às 16 semicolcheias de um compasso simples quatro por quatro. Nas caixas vazias, a posição espacial dos ataques sonoros num determinado instrumento é grifada com uma bola preta. Portanto, esse sistema identifica o ponto da produção sonora e não se preocupa em simbolizar a duração do som.

Ainda em relação à Figura 3, informo que a leitura deve ser feita horizontalmente da esquerda para a direita, o que demonstra ser uma herança da notação musical convencional. Conforme certas pesquisas verificaram, a escrita ocidental não é apropriada para transcrever certas especificidades das músicas de matriz africana. Embora tenha havido um esforço para elaborar uma representação adequada, por meio do pensamento de música aditiva, ${ }^{20}$ as tentativas de grafia dos ritmos ainda são feitas na horizontal.

Então, com o intuito de criar uma notação musical de percussionista para percussionista, que se aproximasse da visão da execução musical, como

\footnotetext{
19 Time Unit Box System.

${ }^{20}$ Enquanto na música divisiva o som é dividido em partes iguais, sucessivamente, na música aditiva toma-se a direção oposta.
} 
se estivesse olhando para o tambor, tomei como referência o jogo da amarelinha. Conforme a Figura 4, a trilha do jogo da amarelinha é percorrida verticalmente de baixo para cima e em movimentos laterais diagonais. Portanto, a Tablatura para Percussão vai adotar esse mesmo princípio.

Além disso, tendo em vista que os ritmos do candomblé ketu e da umbanda utilizam aparentemente apenas dois tipos básicos de divisão rítmica, criei e adotei a analogia da fita métrica. Ou seja, assim como a fita tem uma régua para a escala métrica e outra para polegadas (Figura 5), a Tablatura para Percussão tem uma trilha diferente para a divisão binária/quaternária (Figura 10) e outra para a divisão ternária (Figura 11).

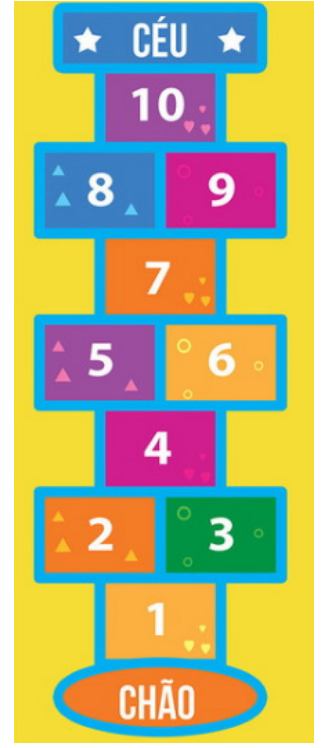

Figura 4: Jogo da amarelinha. Fonte: Jogo... (2020).

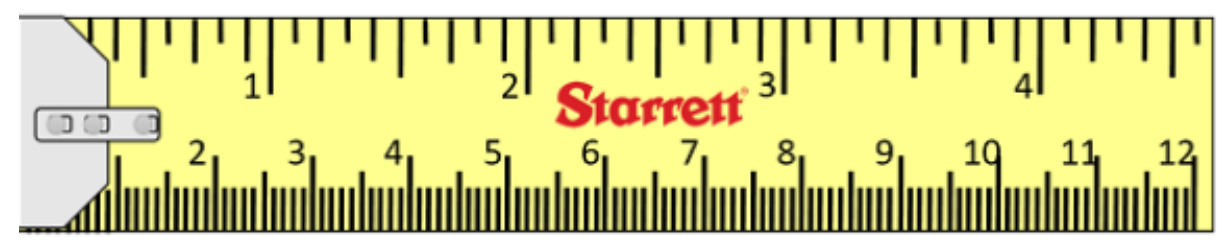

Figura 5: Escala métrica e em polegada. Fonte: Mattede (2014, p. 5).

Para explicar a lógica da construção da Tablatura para Percussão vamos tomar como exemplo um ciclo com 16 pulsações elementares. O primeiro passo foi pegar um conjunto de caixas tipo TUBS e numerá-las (Figura 6).

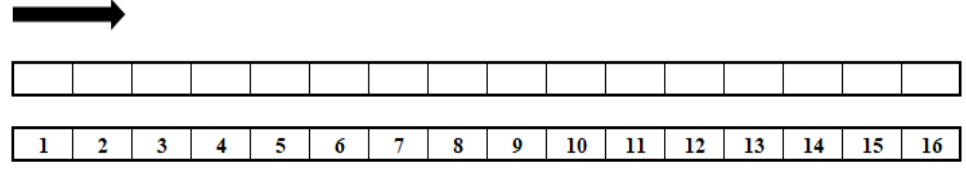

Figura 6: $1^{\circ}$ passo. Fonte: elaboração própria.

Na sequência, as caixas foram rotacionadas para a esquerda até atingir a posição vertical. Nota-se que esse movimento faz com que a sequência numérica fique de baixo para cima (Figura 7). No terceiro passo, o conjunto 
de caixas numeradas é separado diagonalmente em duas colunas (Figura 7). Então, os números ímpares serão tocados pela mão direita e os números pares, pela mão esquerda. No quarto e último passo da formatação estrutural, a tablatura recebe as legendas ME (mão esquerda) e MD (mão direita), bem como os números de 1 a 4 acompanhados de um traço horizontal. O objetivo é demonstrar que o ciclo rítmico tem quatro partes com tamanhos iguais. A priori, sugere-se evitar a contagem dessa numeração. A tablatura com 12 pulsações elementares para a divisão ternária foi elaborada da mesma maneira. A partir de agora usarei o termo "células" no lugar de "caixas".
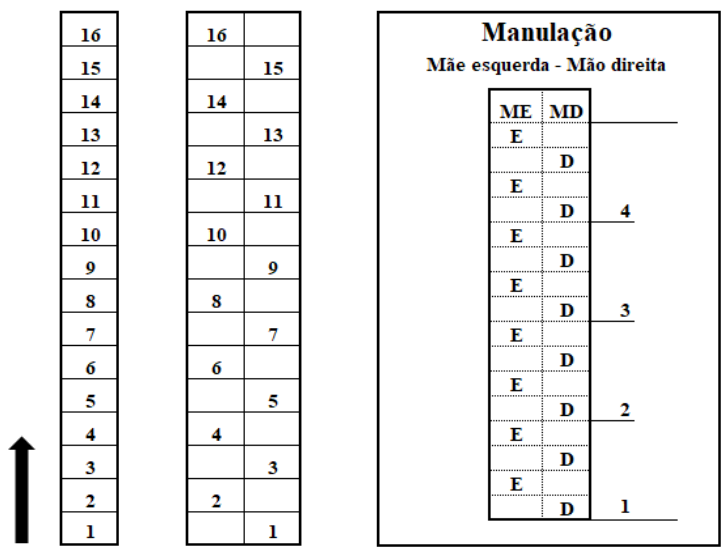

Figura 7: $2^{\circ}, 3^{\circ}$ e $4^{\circ}$ passos.

Fonte: elaboração própria.

Resumindo, a Tablatura para Percussão é um tipo de notação que utiliza uma grafia alternativa para representar alguns parâmetros previstos na escrita convencional como a fórmula de compasso e figuras rítmicas, sem precisar mencioná-los. Porém, procura se aproximar da realidade dos percussionistas e para tal fornece a manulação e os timbres que são tocados nos instrumentos. Como dito anteriormente, na umbanda e no candomblé ketu, os atabaques são manipulados de jeitos diferentes e por conta disso a legenda dos timbres será apresentada separadamente.

\section{TABLATURAS PARA UMBANDA}

Será apresentado agora os ritmos mais tocados em rituais de umbanda nos terreiros ${ }^{21}$ situados no Vale do Itajaí. Nestes exemplos serão destacadas as bases dos ritmos, pois os repiques ou variações rítmicas ocorrem livremente

\footnotetext{
${ }^{21}$ Tenda de Umbanda Caboclo Ubirajara Flecheiro, Tijucas; Alaketu Asé Odó Alasan, Penha; llê Asé Yemonjá Ygbô, Itapema; Centro de Umbanda São Sebastião, Templo de Ogum Beira Mar, Terreiro de Mãe Vânia e Ilê Alaketu Onirá Asé, Itajaí; Ilê Samba Abaíra, Balneário Camboriú; Ilê Asé Omi Osun, Brusque; e Terreiro de Mãe Lia, Navegantes.
} 
conforme a habilidade de cada percussionista. Diferentemente do candomblé ketu, os toques na umbanda não precisam marcar os passos da dança e por conta disso a execução musical é mais flexível. Além disso, independentemente da quantidade de atabaques disponiveis numa casa, na umbanda não há uma regra, na maioria dos casos todos os tambores tocam a mesma "levada". ${ }^{22}$ Informo que o mesmo ritmo pode receber nomes diferentes em outros terreiros. Na Figura 8, é apresentada a notação dos toques Umbandão e Nagô.

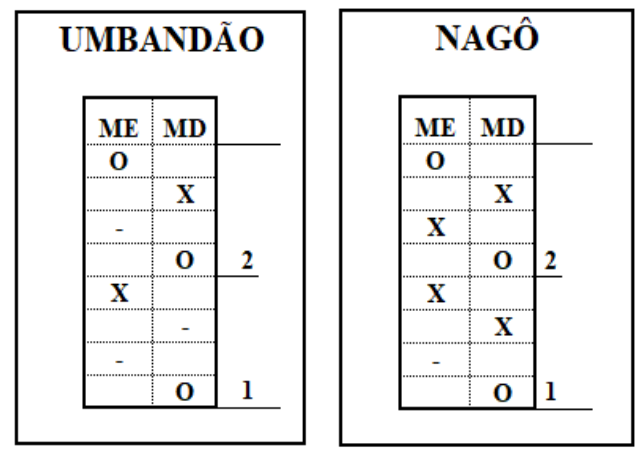

Figura 8: Toques Umbandão e Nagô. Fonte: elaboração própria.

Como eles possuem uma estrutura parecida serão abordados juntos. Conforme visto anteriormente, a tablatura é formada por duas colunas, $\mathrm{ME}$ e MD, nas quais são anotados apenas os sons mais importantes, da seguinte forma: a letra "O" simboliza o som médio, o som aberto tocado na borda do atabaque; a letra " $\mathrm{X}$ " corresponde ao som mais agudo, obtido com a técnica de slap; e as células indicadas com um traço indicam as notas de preenchimento, as quais podem ser evitadas. Nota-se que o ciclo rítmico dos toques Umbandão e Nagô têm a extensão de oito pulsações elementares. Frisa-se que todos os ritmos apresentados neste trabalho são circulares, o que significa que eles ficam se "repetindo' enquanto são entoadas as cantigas.

Na Figura 9, temos o toque Angola, um dos mais tocados, também chamado de Samba de Cabula ou Cabula, com algumas variações encontradas, que entendo como sotaques de tambor. Esse toque tem um ciclo rítmico com 16 pulsações elementares. Em relação à estrutura sonora do Angola e do Cabula, identificamos que a segunda metade é praticamente um espelho da primeira. Então, a Tablatura para Percussão também pode ser usada para análises musicais. Em alguns terreiros o toque Umbandão é tocado como uma base do Angola.

\footnotetext{
22 O mesmo que ritmo na linguagem popular.
} 

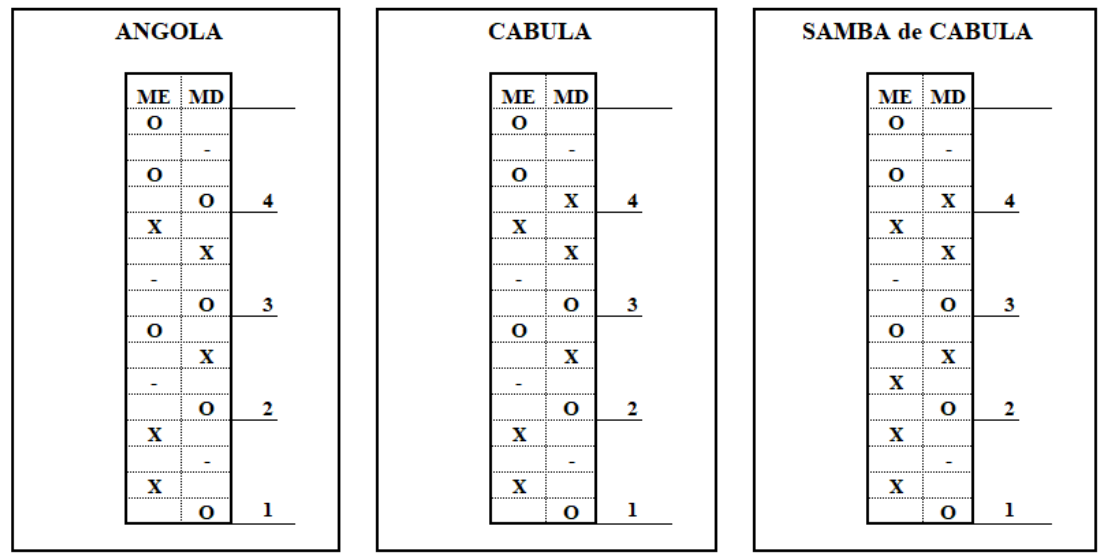

Figura 9: Toque de Angola, Cabula e Samba de Cabula.

Fonte: elaboração própria.

Em relação ao andamento, os ritmos até agora apresentados são tocados mais cadenciados, de lento a médio. Por outro lado, os toques Congo de Ouro e Barravento são tocados em andamentos mais medianos e rápidos, principalmente o segundo, que é o mais rápido e mais forte de todos. Na Figura 10, temos a tablatura para o ritmo Congo de Ouro com as quatro bases mais encontradas.

Entretanto, nos terreiros foi possivel encontrar diferentes situações de arranjo. Por exemplo, um percussionista pode tocar todas as bases numa mesma cantiga ou todos os músicos tocam juntos uma única base. Além disso, em algumas casas religiosas que possuem muitos tambores, chegando a cinco atabaques, foi visto cada um tocar simultaneamente bases distintas na mesma cantiga.
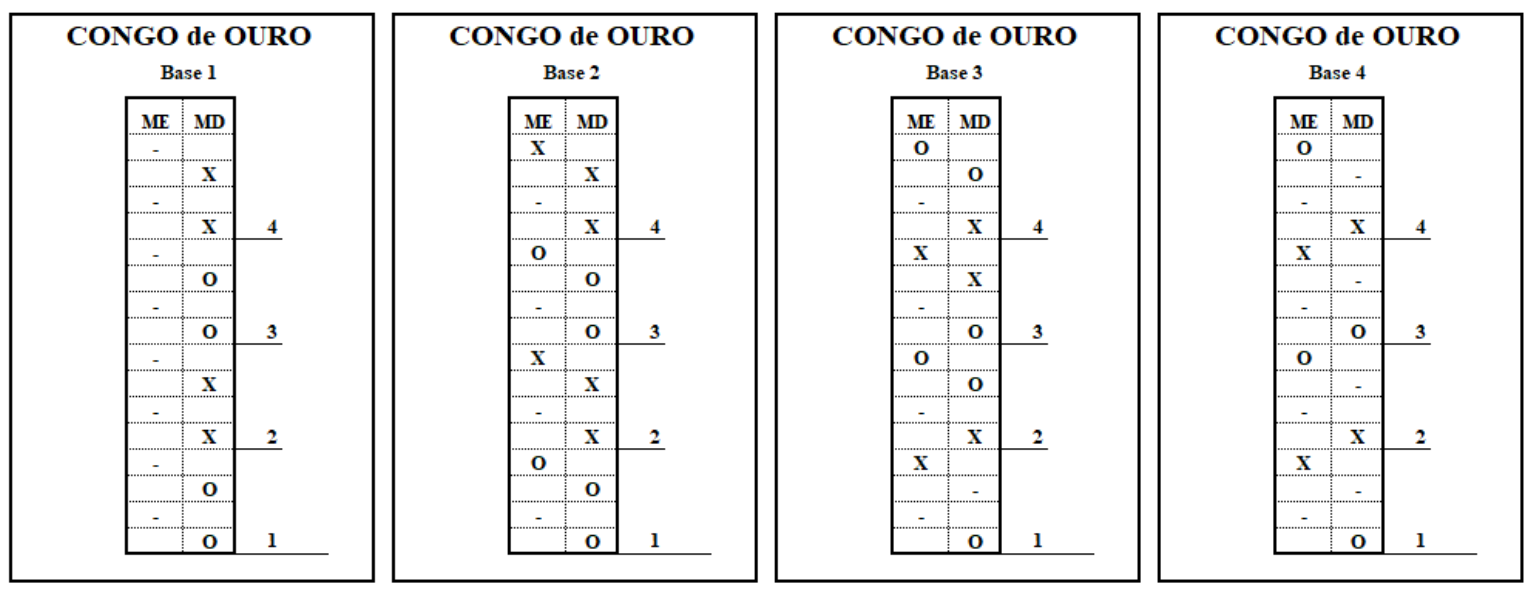

Figura 10: Toque de Congo de Ouro. Fonte: elaboração própria.

Outro ponto relevante é que, à medida que o Congo de Ouro fica mais rápido, a tendência é tocar apenas a terceira e quarta base. Ademais, apesar de a estrutura sonora do Congo de Ouro parecer estar repetida, explica-se que, por conta da extensão da sua linha-guia, foi utilizada uma trilha com 
16 pulsações elementares. A título de ilustração, a linha-guia do Congo de Ouro é a mesma linha-guia do maculelê, do avamunha do candomblé, do ritmo "avenida" do carnaval baiano, do candombe uruguaio e do son cubano (Figura 3). Por fim, o Barravento é o último toque de umbanda a ser abordado. Como já foi dito, esse é o ritmo mais rápido e mais "quente" (Figura 11).
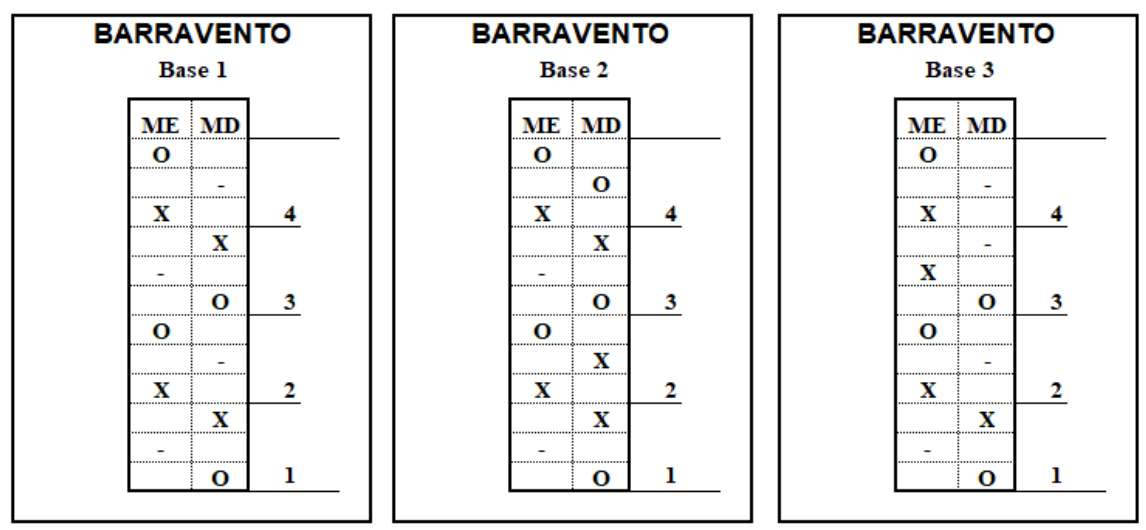

Figura 11: Toque de Barravento. Fonte: elaboração própria.

$\mathrm{Na}$ pesquisa foram vistas poucas variações de uma mesma base. Os fraseados estão mais ligados à experiência dos músicos. Como a linha-guia do Barravento é igual a linha-guia do vassi invertida $[\mathbf{X} . \mathbf{X} . \mathbf{X} . \mathbf{X} \mathbf{X} . \mathbf{X} . \mathbf{X}]$, a tablatura foi feita numa trilha com 12 pulsações elementares, e, portanto, utiliza uma divisão ternária. Informo que o Barravento e o Congo de Ouro são originários do candomblé de Angola.

\section{TABLATURAS PARA CANDOMBLÉ KETU}

Nos terreiros de candomblé ketu, os rituais refletem o caráter de uma religião assentada em fundamentos seculares e tradicionais. Nesse ambiente, os eventos públicos são movidos por uma complexidade musical que envolve uma grande variedade de ritmos, hierarquia percussiva, "solos" do atabaque rum que marcam os gestos dos orixás, danças com narrativas mitólogicas, cantigas na língua iorubá, um repertório extenso e "fechado", bem como indumentárias e objetos simbólicos.

Os ritmos tocados no candomblé ketu são originários de diversas etnias ${ }^{23}$ que vieram da África para o Brasil, e alguns poucos são tocados com as mãos no couro do tambor, enquanto a grande maioria é tocada com varetas, as aguidavis. Destes últimos, serão destacados os mais tocados, ${ }^{24}$ como o vassi,

\footnotetext{
${ }^{23}$ Exemplos: ketu, jeje e ijexá.

${ }^{24}$ Segundo Lühning (1990, p. 120), os ritmos mais tocados no candomblé ketu são o [vassi] corrido (50\%), o agueré (20\%), o jinká (20\%) e o ijexá (10\%).
} 
agueré e jinká; e o opanijé. Em relação ao ciclo rítmico, o vassi (Figura 12) tem 12 pulsações elementares e o opaninjé (Figura14) tem 16. Por conta da relação com o ciclo da dança e com o tamanho das frases musicais do atabaque rum, o agueré (Figura 15) e o jinká (Figura 13) foram escritos dobrados e têm respectivamente, 16 e 12 pulsações elementares.

Conforme podemos observar nas figuras 12, 13, 14 e 15, a tablatura para a base rítmica, gã lé e rumpi, é formada por duas colunas, ME e MD, enquanto o atabaque rum recebe uma terceira coluna, LG, a linha-guia (Figura 16). Ressalta-se que nos tambores lé e rumpi, as duas mãos produzem o mesmo timbre, simbolizado pela letra xis, sendo " $X$ " para os sons principais e " $\mathrm{x}$ " para os complementares. É bom lembrar que a leitura musical deve ser feita de baixo para cima. Por conta da questão da linha-guia, percorre-se a trilha das células preenchidas. Portanto, para os ritmos do candomblé ketu, a diagonalidade só é usada quando possivel. Os números que identificam as partes dos ritmos foram retirados, pois o objetivo final é simplificar ao máximo.

GÄ

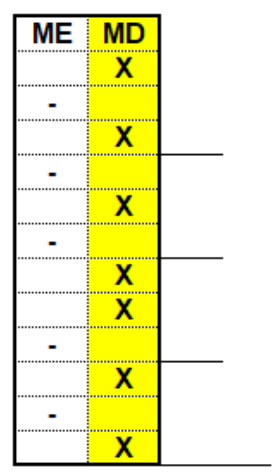

LÉ

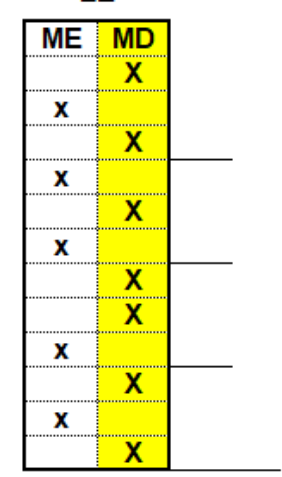

RUMPI

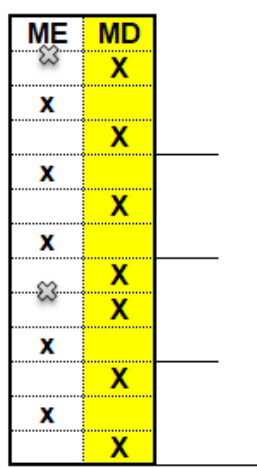

Figura 12: Ritmo vassi. Fonte: elaboração própria.

GÄ

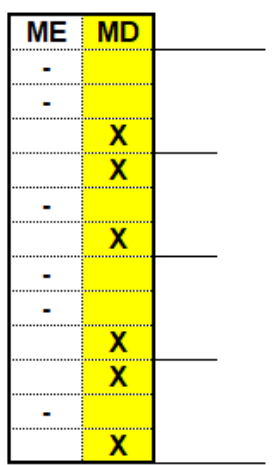

LÉ

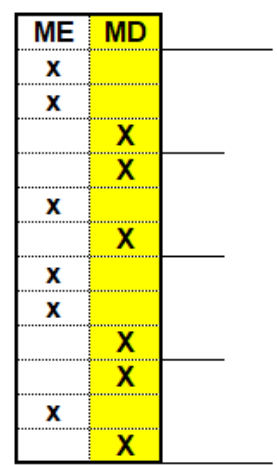

RUMPI

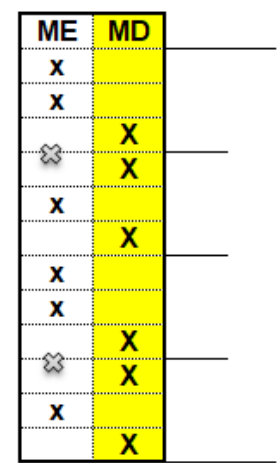

Figura 13: Ritmo jinká. Fonte: elaboração própria. 

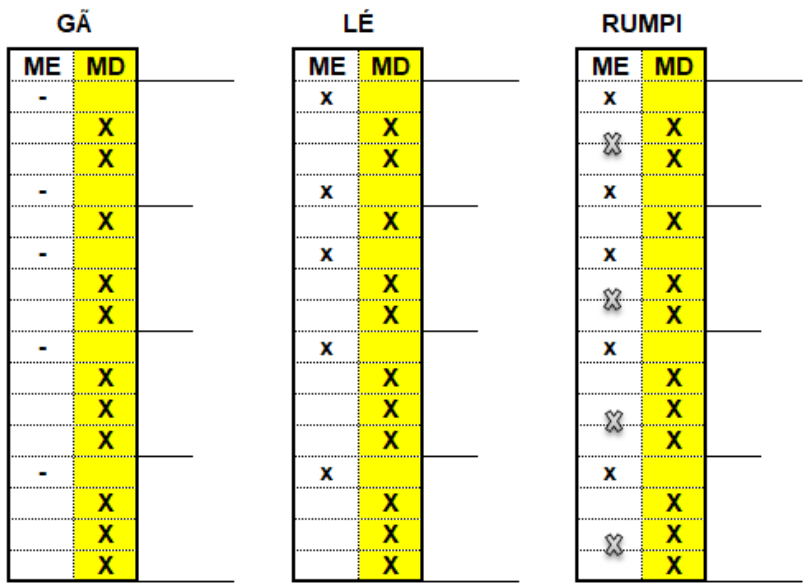

Figura 14: Ritmo opanijé.

Fonte: elaboração própria.

É possivel verificar também que esses ritmos possuem uma estrutura semelhante. Conforme já citado, a linha-guia é tocada no gã e reforçada pela mão direita (MD) nos atabaques lé e rumpi, os quais ainda executam notas complementares com a mão esquerda (ME), montando assim uma base rítmica para os fraseados do rum. Cabe ressaltar que a coluna da direita da tablatura está na cor amarela para destacar essa peculiaridade da maioria dos ritmos do candomblé ketu. Quando esse "estilo ketu" de tocar é entendido, torna-se mais fácil a aprendizagem. Ademais, mediante uma abordagem etnomusicológica, acrescento que esses ritmos podem ser caracterizados pela complementaridade.

Ainda como parte desta linguagem musical, o rumpi executa a mesma frase do lé, porém adiciona uma nota extra, normalmente entre a nota curta e a nota longa da linha-guia. É importante destacar que essa nota extra ${ }^{25}$ não se trata de um flam, ${ }^{26}$ sendo na verdade uma terceira nota, o que os percussionistas chamam de repique. A frase do rumpi é também chamada de base com repique.

Por questões didáticas, encerro esta seção do candomblé ketu apresentando a base do ritmo agueré (Figura 15) e dois trechos não sucessórios da tablatura do atabaque rum ${ }^{27}$ (Figuras 16 e 17).

\footnotetext{
${ }^{25}$ Essa nota extra está grafada com um " $\mathrm{X}$ " diferente, que aparece na coluna ME.

26 Tipo de rudimento tocado pelos bateristas.

${ }^{27}$ A coluna da esquerda ( $L G$ = linha-guia) foi adicionada para facilitar a transcrição. É bom lembrar que a linha-guia é tocada no gã por outro percussionista.
} 
GÄ

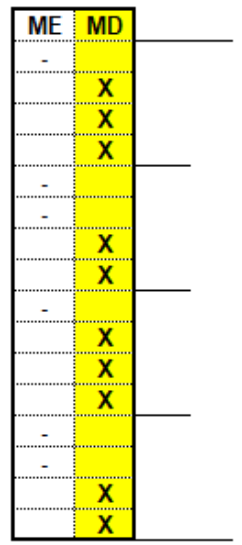

LÉ

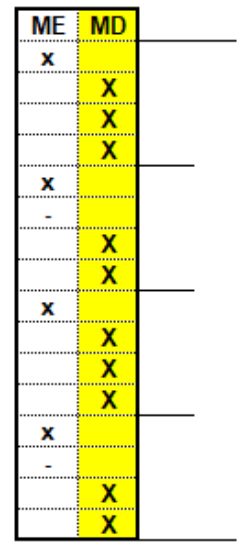

RUMPI

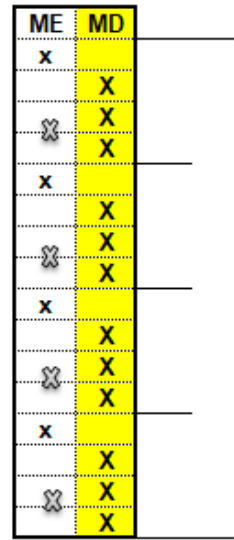

Figura 15: Ritmo agueré.

Fonte: elaboração própria.

É importante lembrar que esse tambor exerce o papel de solista, e, portanto, executa uma sequência de frases musicais diferentes em cada cantiga. As características do atabaque rum não serão tratadas neste artigo, porém é importante frisar que esse tambor toca uma narrativa musical que está diretamente relacionada com a mitologia, o texto das cantigas e a dança dos orixás. Além disso, diante da especificidade da articulação, nele é possivel tirar sete sons diferentes (Calabrich; Silva, 2017, p. 7) ou até 11 (Cardoso, 2006, p. 75).
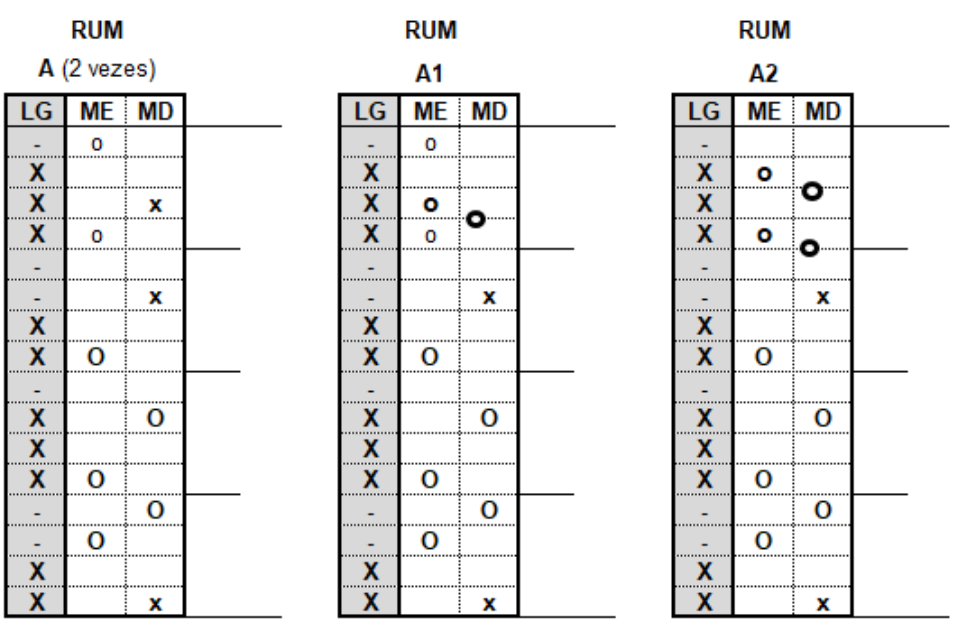

Figura 16: Ritmo agueré. Rum. Trecho 1. Fonte: elaboração própria. 

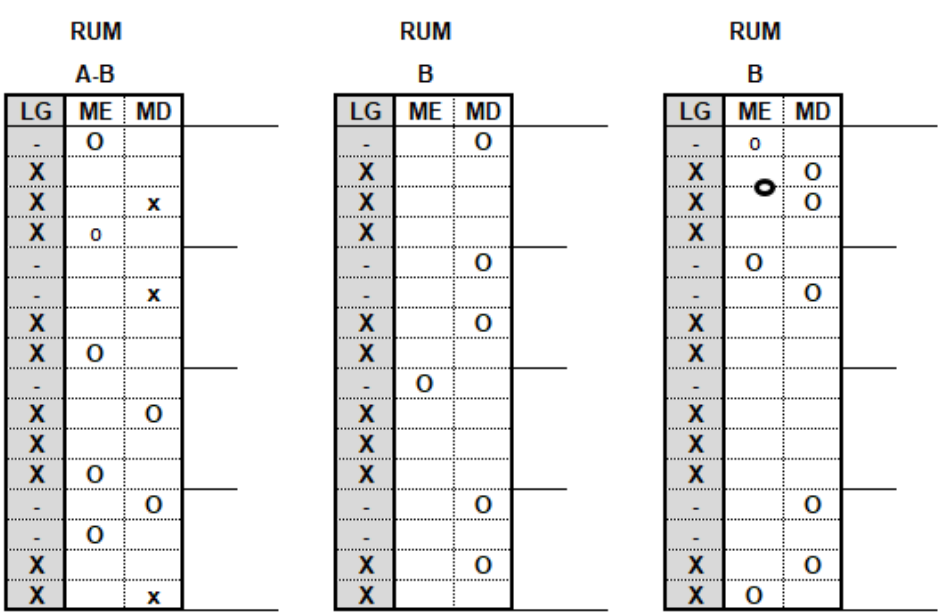

Figura 17: Ritmo agueré. Rum. Trecho 2. Fonte: elaboração própria.

Então, como a Tablatura para Percussão procura ser um modelo de notação simplificada, para dar conta da complexidade do rum é necessário ter bastante conhecimento idiomático do instrumento e experiência religiosa. De qualquer modo, visando facilitar a leitura, em termos de legenda, ${ }^{28}$ informo que a letra "O" corresponde aos sons graves e a letra "X", aos sons agudos. Explico que o tamanho das letras está relacionado com os acentos musicais e que as notas de preenchimento não foram grifadas. Por fim, lembro que a mão esquerda toca diretamente na pele do tambor e que a mão direita toca o atabaque com uma aguidavi, o que permite diversas combinações sonoras.

\section{CONSIDERAÇÕES FINAIS}

O estudo ora apresentado é resultado do encontro de duas epistemologias da área de pesquisa em música, que se juntam para propor um modelo de notação alternativa para os instrumentos de percussão popular, em especial para os atabaques da umbanda e do candomblé ketu. Por um lado, foi mostrada a etnomusicologia atenta às questões culturais, religiosas, às funções da música, aos instrumentos e parâmetros rítmicos, enquanto a educação musical contribuiu com o olhar atento aos processos de ensino/aprendizagem, às dificuldades, desafios, materiais e sistematização.

Nesse caminho, os ritmos da umbanda e do candomblé ketu foram estudados em paralelo porque na região do Vale do Itajaí, litoral norte de Santa Catarina, é comum encontrar casas religiosas que pratiquem as duas doutrinas, porém com calendários distintos. Por isso, apesar das diferenças musicais, entre ritmos e formas de tocar, o contexto local favoreceu o exercício de

\footnotetext{
${ }^{28}$ Seguindo o padrão dos atabaques lé e rumpi, normalmente no rum não são tocadas notas do tipo flam, sendo na verdade outras notas. Ou seja, na tablatura do rum, as notas com grafia diferenciada, negrito ou bolinhas sobre a linha, indicam essas notas extras ou detalhes do "sotaque ketu", os quais devem ser associados com a prática musical.
} 
pensar num único padrão de notação. O processo também foi favorecido pelo fácil acesso ao universo dos terreiros e pela experiência do campo acumulada nos últimos anos.

Nas duas religiões abordadas, continua o senso de preservação da tradição, cada qual com as suas especificidades. No entanto, tendo em vista o dinamismo das culturas, certas práticas internas acabam mudando com o tempo. A vida muda e as possibilidades de ensinar e aprender também. Nessa trilha, na qual a oralidade é a base fundamental, a comunidade religiosa tem feito uso da escrita e da tecnologia para adquirir, registrar e compartilhar conhecimento, entre eles, a música.

Porém se detecta que, independentemente de uma "oralidade antiga" ou "oralidade moderna", o ensino dos ritmos tocados nos atabaques ainda acontece na maioria dos casos sem a presença de um tipo de notação musical, com raras exceções. Ademais, percebe-se que em muitas cidades e terreiros, há uma carência na sistematização dos ritmos, como também de encontrar e manter os percussionistas. Por outro lado, muitas pessoas, homens e mulheres, crianças e adultos, mostram-se interessados pelo aprendizado dos ritmos, como também muitos regentes espirituais têm incentivado o estudo e a organização de oficinas de percussão.

Por conta de tudo isso, a Tablatura para Percussão proposta aqui foi elaborada para ser um modelo de notação musical alternativa que facilite a aprendizagem e difusão dos ritmos tocados nos atabaques da umbanda e do candomblé ketu. Por isso, o objetivo foi utilizar uma grafia simples, rápida e sintética, que considerasse os principais parâmetros rítmicos das músicas de matriz africana, sem deixar de lado elementos importantes da notação musical convencional.

Além disso, cabe informar que a tablatura desenvolvida para os atabaques pode ser aplicada para tambores similares, como por exemplo, o djembé, timbal, tumbadora; pode ser adaptada para outros instrumentos como o cajón, caixa, tamborim, agogô, surdo, trio de surdos-axé, etc. Pode também ser utilizada para ensinar outros ritmos da cultura musical afro-brasileira, tais como a capoeira, o jongo, congado mineiro, cacuriá, samba, samba de roda, samba-reggae, maracatu, etc.; e de outras práticas afrorreligiosas.

Por fim, almeja-se que esse trabalho possa de alguma forma inspirar outras pesquisas sobre a música percussiva afro-brasileira, e que os ritmos tocados nos terreiros continuem sendo observados, escutados, cantados, repetidos e ecoados em diferentes espaços, em diversos tipos de materiais e tecnologias, e que forneça novos significados às práticas pedagógicas. 


\section{REFERENCIAS}

AGAWU, Kofi. structural analysis or cultural Analysis? Competing perspectives on the "standard pattern" of West African rhythm. Journal of the American Musicological Society, [s. l.], v. 59, n. 1, p. 1-46, 2006.

ALMEIDA, M. Berenice; PUCCI, Magda Dourado. Outras terras, outros sons: um livro para o professor. 2. ed. São Paulo: Callis, 2011.

AROM, Simha. Modelización y modelos en las músicas de tradición oral. In: CRUCES, Francisco et al. (ed.). Las culturas musicales: lecturas de etnomusicologia. Madrid: Editorial Trotta, 2001. p. 203-232.

ARROYO, Margarete. Um olhar antropológico sobre práticas de ensino e aprendizagem musical. Revista da Abem, Porto Alegre, n. 5, p.13-20, 2000.

BARROS, José Flávio Pessoa de. O banquete do Rei Olubajé: uma introdução à música afro-brasileira. Rio de Janeiro: Ao Livro Técnico, 2009a.

BARROS, José Flávio Pessoa de. A fogueira de Xangô, o orixá do fogo: introdução à música afro-brasileira. Rio de Janeiro: Ao Livro Técnico, 2009b.

BASTIDE, Roger. O candomblé da Bahia: rito nagô. São Paulo: Companhia das Letras, 2001.

BENISTE, José. Mitos yorubás: o outro lado do conhecimento. Rio de Janeiro: Bertrand Brasil, 2001.

BLACKING, John. Música, cultura e experiência. Cadernos de Campo, São Paulo, n. 16, p. 201-218, 2007.

BRAGA, Reginaldo Gil. Batuque Jêje-Ijexá em Porto Alegre: a música no culto dos orixás. 1997. Dissertação (Mestrado em Música) - Escola de Música, Salvador, Universidade Federal da Bahia, 1997.

BRAGA, Reginaldo Gil. Processos sociais de ensino e aprendizagem, performance e reflexão musical entre tamboreiros de nação: possiveis contribuições à escola formal. Revista da Abem, Porto Alegre, n. 12, p. 99-109, 2005.

BRAGA, Reginaldo Gil. Tamboreiros de Nação: música e modernidade religiosa no extremo sul do Brasil. Porto Alegre: UFRGS Editora, 2013.

BRANDÃO, Gersonice Equede Sinha. Equede: a mãe de todos: Terreiro Casa Branca. Organização Alexandre Lyrio e Dadá Jaques. Salvador: Barabô, 2015.

BRUNDAGE, Kirk. Afro-Brazilian percussion guide: instruments and rhythms from Salvador, Bahia, Brazil. Los Angeles: Quality Books, 2010. 
CACCIATORE, Olga Gudolle. Dicionário de cultos afro-brasileiros. Rio de Janeiro: Forense Universitária, 1977.

CALABRICH, Selma; SILVA, Gerson (org.). Afrobook: mapeamento dos ritmos afro baianos: volume 1. Salvador: Pracatum Escola de Música e Tecnologia, 2017.

CARDOSO, Ângelo Nonato Natale. A linguagem dos tambores. 2006. Tese (Doutorado em Música) - Escola de Música, Salvador, Universidade Federal da Bahia, 2006.

FARIAS, Rafael Rolim. A música brasileira: uma abordagem didáticopoética das canções no samba de roda, no reisado e no coco. In: A MÚSICA da educação básica: material de apoio à implantação da lei 11.769/08. Salvador: Edufba, 2011. p. 135-157.

FONSECA, Edilberto José de Macedo. O toque do gã: tipologia preliminar das linhas-guias do candomblé Ketu-nagô no Rio de Janeiro. 2003. Dissertação (Mestrado em Música Brasileira) - Escola de Música, Universidade Federal do Rio de Janeiro, Rio de Janeiro, 2003.

GARCIA, Sonia Maria Chada. Um repertório musical no seio do culto aos orixás, em Salvador-BA. 2001. Tese (Doutorado em Música) - Escola de Música, Salvador, Universidade Federal da Bahia, 2001.

GOHN, Maria da Glória. Educação não-formal, participação da sociedade civil e estruturas colegiadas nas escolas. Ensaio, Rio de Janeiro, v. 14, n. 50, p. 27-38, 2006. Disponivel em: https://doi.org/10.1590/S010440362006000100003. Acesso em: 10 fev. 2018.

GUERREIRO, Goli. A trama dos tambores: a música afro-pop de Salvador. São Paulo: Ed. 34, 2000. (Coleção Todos os Cantos).

HEIN, Ethan. Circular rhythm visualizations. [S. l.: s. n.], 2015. Disponivel em: https://pt.slideshare.net/ ethanhein/ circular-rhythm-talk/9. Acesso em: 1 mar. 2020.

HOOD, M. The challenge of "bi-musicality". Ethnomusicology, [s. l.], v. 4, n. 2, p. 55-59, 1960.

JOGO da amarelinha. Blog do Elo7. São Paulo: Elo7, 2020. Disponível em: https://www.elo7.com.br/promocao-imperdivel-adesivo-jogo-de-amarelinha68x180 cm/dp/F67D76. Acesso em: 14 abr. 2020.

KLEBER, Magali. A prática da educação musical em ONGs: dois estudos de caso no contexto urbano brasileiro. Tese (Doutorado em Música). UFRGS, 2006. 
KLEBER, Magali. Aspectos das políticas públicas educacionais e o papel da ABEM no panorama brasileiro. Revista da Abem, Londrina, v. 20, n. 28, p. 27-34, 2012.

KOETTING, James. Analysis and notation of West African drum ensemble music. Selected reports in Ethnomusicology, [s. l.], v. 1, n. 3, p. 115-46, 1970.

KUBIK, Gerhard. Educação tradicional e ensino da música e dança em sociedades tradicionais africanas. Revista de Antropologia, São Paulo, v. 22, p. 107-112, 1979.

LACERDA, Marcos Branda. Música instrumental no Benim: repertório fon e música batá. São Paulo: Ed. USP, 2014.

LODY, Raul; SÁ, Leonardo. O atabaque no candomblé baiano. Rio de Janeiro: Funarte, 1989.

LÜHNING, Angela. A música no candomblé nagô-ketu: estudos sobre a música afro-brasileira em Salvador, Bahia. Hamburgo: Verlag der Musikalienhandlung Karl Dieter Wagner, 1990.

LUNELLI, Diego Conto. Processo de ensino/aprendizagem em casa de religião: um estudo de caso. In: CONGRESSO NACIONAL DA ABEM, 22., 2015, Natal. Anais [...]. Natal: Abem, 2015.

MÃE STELLA DE ÒȘÓSI. Òșósi: o caçador de alegrias. Salvador: Secretaria da Cultura e Turismo, 2006.

MATTEDE, Henrique. Trenas, o que é? Como usar? Ferramentas para eletricista. Belo Horizonte: Mundo da Elétrica, 2014. Disponivel em: https:// www.mundodaeletrica.com.br/trenas-o-que-e-como-usar-ferramenta-paraeletricista/. Acesso em: 1 mar. 2020.

MAURÍCIO, George. O candomblé bem explicado (Nações Bantu, Iorubá e Fon). Orgabização Marcelo Barros. Rio de Janeiro: Pallas, 2009.

MERRIAM, Alan. The anthropology of music. Evanston: Northwestern University Press, 1964.

MONTEIRO, Marcelo dos Santos. Curso afro-brasileiro de toques, cânticos e danças. Apostila. Rio de Janeiro: Centro de Tradições Afro-Brasileiras, 1995.

NKETIA, J. H. Kwabena. The music of Africa. New York: Norton \& Company, 1974.

OGBEBARA, Awofa. Igbadu: a cabaça da existência: mitos nagôs revelados. Rio de Janeiro: Pallas, 1998. 
OLIVEIRA, Altair B. Cantando para os orixás. 4. ed. Rio de Janeiro: Pallas, 2012.

OLIVEIRA PINTO, Tiago de. As cores do som. Estrutura sonora e concepções estéticas na música afro-brasileira. África, São Paulo, v. 22/23, p. 87-110, 2001.

A ORQUESTRA do candomblé da nação ketu: um estudo afro-brasileiro de Hank Schroy, Bira Reis, e os Alabês de Ilê-Oxumaré. Salvador: Oficina de Investigação Musical, 2011. 1 DVD (149 min).

PEÑALOSA, David. The clave matrix, Afro-Cuban rhythm: its principles and African origins. Redway: Bembe, 2009.

PRANDI, Reginaldo. Segredos guardados. São Paulo: Companhia das Letras, 2005.

PRASS, Luciana. Saberes musicais em uma bateria de escola de samba: uma etnografia entre os Bambas da Orgia. Porto Alegre: Editora UFRGS, 2004.

QUEIROZ, Luiz Ricardo Silva. Educação musical e etnomusicologia:

caminhos, fronteiras e diálogos. Opus, Goiânia, v. 16, n. 2, p. 113-130, dez. 2010.

REIS, Alcides Manoel dos. Candomblé: a panela do segredo. Organização Rodnei William Eugênio. São Paulo: Editora Arx, 2000.

SANDRONI, Carlos. Feitiço decente: transformações do samba no Rio de Janeiro, 1917-1933. Rio de Janeiro: Jorge Zahar, 2001.

SANTOS, José Luiz. O que é cultura. São Paulo: Brasiliense, 2006. (Coleção primeiros passos, 110).

SANTOS, Maria Stella de Azevedo. Meu tempo é agora. 2. ed. Salvador: Assembleia Legislativa do Estado da Bahia, 2010.

. Mãe Stella de Oxossi: uma vida em movimento. [S. l.: s. n.], 2017. Aplicativo para celular

SANTOS, Maria Stella de Azevedo; PEIXOTO, Graziela Domini. O que as folhas cantam: para quem canta folha. Salvador: Secretaria de Politicas Culturais, 2014.

SENA, Severino. Cantando e tocando ijexá e barra-vento. Madras: São Paulo, 2014.

Na gira da umbanda: nos toques de angola e congo. São Paulo:

Madras, 2015. 
SENA, Severino. $A B C$ do ogã: o valor da curimba na umbanda. São Paulo: Madras, 2017.

SILVA, Luiz Carlos de Oliveira; VICENTE, Tânia. Ritmos do candomblé: songbook. Rio de Janeiro: Abbetira Arte e Produções, 2008.

TYLOR, Edward Burnett. Primitive culture: researches into the devolopment of mythology, philosophy, religion language, art, and custom. London: Gordon Press, 1871.

VALLADO, Armando. Iemanjá, a grande mãe africana do Brasil. Rio de Janeiro: Pallas. 2008.

WILLE, Regiana Blank. Educação musical formal, não formal ou informal: um estudo sobre processos de ensino e aprendizagem musical de adolescentes. Revista da Abem, Porto Alegre, n. 13, p. 39-48, 2005. 
Luciano da Silva Candemil é natural de Florianópolis. Atua como músico, percussionista, compositor, professor, pesquisador e produtor musical. Atualmente é doutorando em Etnomusicologia na Universidade Federal do Paraná (UFPR) e bolsista Capes. Tem mestrado em Etnomusicologia na Universidade do Estado de Santa Catarina (Udesc). Tem as seguintes titulações na Universidade do Vale do Itajaí (Univali): especialização em Educação Musical, licenciatura em Música e bacharelado em Música (Percussão Popular). Pesquisa e desenvolve projetos relacionados aos ritmos de matriz africana fazendo a interface entre a educação musical, etnomusicologia e a dimensão artística. https://orcid.org/0000-0002-7950-5241 